\title{
CONTROLE, INTERVENÇÃO E NECROPOLÍTICA: UMA TOPOGRAFIA DA VIOLENCIA URBANA NAS FAVELAS DO RIO DE JANEIRO
}

\author{
Morgana Paiva Valim ${ }^{1}$ \\ Mariana de Freitas Rasga ${ }^{2}$
}

\section{RESUMO:}

O objeto deste trabalho insere-se na promoção de uma problematização sobre a violência nas favelas do Rio de Janeiro. A gestão do espaço urbano e do controle da população favelada têm sido feitas a partir da produção do medo e violência. Fato que nos leva a crer na existência de uma necropolítica seja por aspectos sociais, seja por marcadores raciais. Além disso, a violência na cidade deve ser analisada sob o prisma da Intervenção Federal e da projeção de possível responsabilidade internacional do Estado brasileiro por violações aos direitos humanos.

Palavras-chave: violência, urbana, favela, gestão policial, necropolítica.

\section{CONTROL, INTERVENTION AND NECROPOLITICS: A TOPOGRAPHY OF URBAN VIOLENCE IN THE FAVELAS OF RIO DE JANEIRO}

\begin{abstract}
:
The purpose of this paper is to promote a problematization of violence in the favelas of Rio de Janeiro. The management of urban space and the control of the favela population have been made from the production of fear and violence. This fact leads us to believe in the existence of a necropolitic either by social aspects, or by racial markers. In addition, violence in the city is analyzed under the prism of the Federal Intervention and the projection of possible international responsibility of the Brazilian State for violations of human rights.
\end{abstract}

Keywords: violence, urban, favela, police management, necropolitics.

\section{INTRODUÇÃO}

A favelização não é um fenômeno recente tampouco desimportante. Demonstrar marcadores excludentes do espaçamento urbano é referir-se a um processo de precarização, de

\footnotetext{
${ }^{1}$ Doutoranda do Programa de Pós-Graduação em Direito da Universidade Veiga de Almeida. Mestre em Direito do Programa de Pós-Graduação da Universidade Gama Filho. Professora Auxiliar da Universidade Veiga de Almeida. mp_valim@hotmail.com. http://lattes.cnpq.br/0747586676976718.

2 Bolsista do Programa Produtividade da Universidade Estácio de Sá. Doutoranda do Programa de Pós-Graduação em Direito da Universidade Veiga de Almeida. Mestre em Direito do Programa de Pós-Graduação da Universidade Veiga de Almeida. Professora Auxiliar da Universidade Estácio de Sá e da Universidade Veiga de Almeida. mfrasga@hotmail.com. http://lattes.cnpq.br/7335276875695463.
} 
segregação e deterioração da dignidade humana. Viver na malha urbana periférica é estar diante de um estado de ausências constitucionais.

De um modo geral, observar as favelas é enxergar a crise que dramaticamente aprofunda o abismo no espaço urbano. O cotidiano multidimensional da favela é tido como de degradação socioterritorial. Essa fricção provocada entre os parâmetros urbanísticos legalizados e os movimentos de resistência para a efetivação dos direitos de moradia nos permitem uma multiplicidade de olhares, inclusive para um processo analítico sobre o descaso do poder público para os grandes bolsões de pobreza.

Os equipamentos urbanos tão questionados nas grandes extensões territoriais de moradia são efetivamente sonegados nesse locus de insalubridade social que são as favelas. Não há saneamento básico, não há suficiência em serviços de saúde e educação. Nas favelas os índices de violência e criminalidade talvez encontrem justificativa nessas desequalizações socioespaciais tão debatidas. É o retrato do caos urbano e da persistência diante das omissões injustificadas dos Poderes.

O uso desses territórios pela população empobrecida promove uma ruptura com o processo normalizado de urbanização, fato que desnutre, desampara e desabriga esses cidadãos. Mas, que ao final os une. A unicidade resiste às mazelas.

A garantia da ordem coletiva e do piso vital mínimo existencial é uma realidade que tem sido palco de debates e enfrentamentos no atual cenário social do Brasil. Os dramas sociais e as tramas que envolvem a problematização dos direitos sociais têm revelado que os fundamentos democráticos do Estado de Direito estão relegados à uma categoria de inexpressividade de ações eficazes.

É preciso mencionar que todos os eventos ocorridos, especialmente, no interior das favelas da cidade do Rio de Janeiro, revelam que muitas questões se constituem em ameaças reiteradas à integridade pessoal e patrimonial da população carioca.

Parece-nos ser um lugar condenado às violências de todas as ordens, ou seja, as favelas tem sido palco de sucessivas e frequentes estigmatizações por parte das instituições estatais, especialmente da polícia e, é por isso, que objeto de estudo deste trabalho visa friccionar um debate sobre a (in)governabilidade relacionada no espaço edificado nas favelas e de discutir a existência de um padrão de governança espacial por mortalidade.

Para este trabalho o lugar de invisibilidades e resistência são visualizados a partir de um esforço exaustivo revisional na esfera de uma metodologia bibliográfica sobre o controle, a intervenção e a necropolítica. Por isso, apoia-se em leituras densas sobre violência, 


\section{CONTROLE, INTERVENÇÃO E NECROPOLÍTICA: \\ UMA TOPOGRAFIA DA VIOLÊNCIA URBANA NAS FAVELAS DO RIO DE JANEIRO}

criminalidade e segurança, tudo com vistas à construção e detalhamento dos mecanismos que objetivam uma análise das correlatas mazelas e inconsistências antagônicas aos discursos constitucionais, especialmente a partir da decretação pelo Presidente da República da Intervenção Federal sob a segurança pública no Estado do Rio de Janeiro.

\section{1. “MASSAS SUPÉRFULAS”: EM BUSCA DO INIMIGO}

A literatura demonstra que os moradores são vistos em sua grande parte como suspeitos ou marginais, sem que lhes sejam garantidas à presunção de inocência (RAMOS; MUSUMECI, 2005, p. 84). São considerados “réus” pelo simples fato de serem moradores de favelas ou supostamente aparentarem sinais diacríticos marginalizadores.

As violações de direitos humanos contra os moradores das favelas trazem os ingredientes componentes desse autorretrato marginal e baseiam-se na sentença: preto, pobre e favelado. Evidentemente se percebe que a vida do jovem pobre e negro é menor. É a vida matável e sem valor (AGAMBEN, 2010, p. 134). O Estado se arregimenta e legitima seus agentes para em nome da garantia da lei e da ordem assassinar seus já reconhecidos inimigos.

Para se ter uma ideia, o ex-governador do Rio de Janeiro em entrevista ${ }^{3}$ anunciou seu ponto de vista sob a população favelada da seguinte maneira:

Sou favorável ao direito da mulher de interromper uma gravidez indesejada. Sou cristão, católico, mas que visão é essa? Esses atrasos são muito graves. Não vejo a classe política discutir isso. Fico muito aflito. Tem tudo a ver com violência. Você pega o número de filhos por mãe na Lagoa Rodrigo de Freitas, Tijuca, Méier e Copacabana, é padrão sueco. Agora, pega na Rocinha. É padrão Zâmbia, Gabão. Isso é uma fábrica de produzir marginal. O Estado não dá conta. Não tem oferta da rede pública para que essas meninas possam interromper a gravidez. Isso é uma maluquice só.

\footnotetext{
${ }^{3}$ http://www1.folha.uol.com.br/fsp/cotidian/ff2510200701.htm
} 
Esse desapreço em relação ao cidadão materializa uma lógica onde a pobreza induz um endividamento desses moradores com a sociedade, como se o lastro da pobreza permitisse classificar o morador da favela à categoria das chamadas: “classes perigosas”, que também pode ser constatada por CHALHOUB (2001, p.76).

Importante pontuar que há uma seletividade em relação as formas de implementação da violência. Há um corpo social mais propenso a acatá-la. Tudo isso é acentuado nas favelas, em razão das caras e cores, da idade, do gênero, da cor/raça e do grupo de renda.

O preto, o pobre e o favelado passam a atuar como legítimos representantes da violência e de tudo o que ela pode traduzir.

E, o Estado através da alegação de agir em nome da preservação da paz social e sob o argumento da eliminação do movimento do tráfico de drogas, segue, reforçando o mito da marginalidade.

As constituições dessas forças, nesses lugares, por comando da segurança pública passam a perpetuar a precarização e extermínio da desumanização desses indivíduos pouco rentáveis e sem domesticação. Essa produção de morte em sequência significa aniquilar o “outro”, agora já reconhecido como o “verdadeiro inimigo”.

Nos estudos de MBEMBE (2011, p.135) esse sentenciamento nada mais é do que a face mais visível da necropolítica ${ }^{4}$. A aniquilação da vida que se refere à destruição material dos corpos e populações humanas, julgados como descartáveis e supérfluos, remetendo-os a uma vida matável e sem valor.

O abismo que se funda entre os moradores das favelas estigmatiza sua própria presença na sociedade. Nesse âmbito de análise e partindo do pressuposto de que a invisibilidade dos moradores de favelas é fato marcante, por óbvio são sonegados direitos fundamentais, tais como: à vida, à igualdade de oportunidades, à integridade física, psíquica e moral, à educação, à saúde e à habitação, à liberdade de locomoção, expressão e de opinião entre outros.

Neste desenho social transindividual surge uma problemática em relação ao reconhecimento e sua dimensão de representação para a construção da identidade que é expressada por discursos marginalizadores donde a análise jurídico-antropológica se perfaz através de uma leitura inferiorizadora (TAYLOR, 2000). Desprezando-se por completo o aporte

\footnotetext{
${ }^{4}$ Para o sociólogo camaronês Achille Mbembe o conceito de necropolítica consiste no poder de soberania do Estado de ditar quem deve viver e quem deve morrer.
} 


\title{
CONTROLE, INTERVENÇÃO E NECROPOLÍTICA: UMA TOPOGRAFIA DA VIOLÊNCIA URBANA NAS FAVELAS DO RIO DE JANEIRO
}

das diferenças culturais, sociais e morais existentes entre os indivíduos ou agrupamentos humanos ao contrário do conceito de identidade utilizado por Taylor como sendo:

É aquilo que nós somos, «de onde nós provimos». Assim definido, é o ambiente no qual os nossos gostos, desejos, opiniões e aspirações fazem sentido. Se algumas das coisas a que eu dou mais valor estão ao meu alcance apenas por causa da pessoa que eu amo, então ela passa a fazer parte da minha identidade (TAYLOR, 1998, p. 54).

Segundo os estudos realizados por PERLMAN (1977, p.42) alguns olhares desmitificavam e disseminavam a ideia de que:

(...) a favela é vista como uma aglomeração desordenada de vagabundos desempregados, mulheres e crianças abandonadas, ladrões, bêbados e prostitutas. Esses elementos marginais vivem em condições "subumanas" sem água encanada, esgotos, coleta de lixo, e outros serviços urbanos básicos, num ambiente sujo e insalubre. As favelas, feias como são, prejudicam pitoresco panorama da cidade.

A favela precisa ser disciplinada da conduta delinquente de seus indivíduos. Essa supremacia da vida (FOUCAULT, 2006), de reconfiguração de uma identidade coesa e coletiva passou a ser vista como um problema social insolúvel. Toma assento, o darwinismo social, tudo com vistas à higienização e afastamento de seus moradores dos espaços de socialização urbana.

Para FOUCAULT (2000, p.305):

\begin{abstract}
quanto mais as espécies inferiores tenderem a desaparecer, quanto mais os indivíduos anormais forem eliminados, menos degenerados haverá em relação à espécie, mais eu - não enquanto individuo mas enquanto espécie - viverei, mais forte serei, mais vigoroso serei, mas poderei proliferar. A morte do outro não é simplesmente a minha vida, na medida em que seria minha segurança pessoal; a morte do outro, a morte da raça ruim, da raça inferior (ou do degenerado, ou do anormal), é que vai deixar a vida em geral mais sadia; mais sadia e mais pura.
\end{abstract}

O direito de fazer viver e deixar morrer revela que nessa tessitura social torna difícil encontrar uma solução instantânea para a legitimação desses cidadãos (FOUCAULT, 2000). No entanto, é preciso evoluir para um discurso de erradicação do imaginário coletivo que nas favelas só estão presentes indivíduos integrantes grupos armados e narcotráfico. 
A precarização de condições de vida e liberdades são evidentes no seio coletivo das favelas o que tornam os agentes públicos insensíveis aos argumentos humanísticos e valores sociais. Esses cidadãos foram ao longo de décadas sendo empurrados para as bordas das cidades, através de políticas repressivas de remoção dos grandes centros urbanos, políticas econômicas malfadadas, inexistência de um trato urbano integrador e até mesmo pela pobreza chancelada pelo Estado.

Para o Estado demonstrar sua funcionalidade em relação aos desinteressantes, infames e indesejáveis o achincalhe desumanizador ocorre das mais variadas formas pela autoconferência do Poder Estatal (FOUCAULT, 2003).

Para legitimidade do direito à violência são enfileirados os agentes policiais. O uso da força, o excesso das práticas para a justificação de mecanismos de controle social realizados pelas instituições policiais, demonstram que o modo de “fazer justiça” se socorre de práticas operacionalizadas eivadas de um aparato ilegal. Xingamentos aos moradores, abordagens policiais abusivas, violência sexual contra mulheres até homicídios decorrentes de práticas policiais em desconformidade com a lei são alguns exemplos. A retórica policial de preservar as liberdades e a vida parecem não produzir valor na história coletiva dos moradores de favelas.

Apenas para efeitos numéricos obtidos por levantamento do Instituto de Segurança Pública foram praticados 1124 homicídios decorrentes de intervenção policial somente no ano de $2017^{5}$. Estamos ou não vivendo “Tempos Necropolíticos”?

Essa marca classificadora, difusa e desmedida, que promove de modo indelével o enquadramento de jovens, negros e pobres como marginais. Para a compreensão desses dados é preciso reconhecer que o ritual de combate, malsucedido, praticado pelos policiais excluem e inviabilizam a possibilidade de reconhecimento dos moradores de áreas menos favorecidas de recursos, como as favelas, negam a possibilidade de serem estes cidadãos considerados como de primeira classe.

\section{Segundo afirmação de WERNECK ${ }^{6}$ :}

O Estado do Rio de Janeiro precisa assumir que até agora errou mais do que acertou com relação às políticas de segurança pública. Os números mostram que a insistência na estratégia de operações de “caça” ao tráfico varejista de

\footnotetext{
${ }^{5}$ https://anistia.org.br/noticias/25-dos-assassinatos-rio-de-janeiro-em-2017-foram-cometidos-pela-policia/

${ }^{6}$ https://anistia.org.br/noticias/25-dos-assassinatos-rio-de-janeiro-em-2017-foram-cometidos-pela-policia/
} 


\section{CONTROLE, INTERVENÇÃO E NECROPOLÍTICA: UMA TOPOGRAFIA DA VIOLÊNCIA URBANA NAS FAVELAS DO RIO DE JANEIRO}

drogas ilícitas não reduz a violência e, ainda por cima, faz com que tenhamos a polícia que mais mata e mais morre do Brasil.

Segundo ZACCONE (2015, p. 23-24), “a polícia mata, mas não mata sozinha”, ou seja, é a raiz da violência urbana e promove a morte real e simbólica dos cidadãos. Assim como, essa mesma polícia causa o descrédito do cidadão nos Poderes constituídos, que atualmente se mostram incapazes de debelar esse drama social.

A forma de atuação da polícia militar, o uso de força letal nas abordagens policiais, cuja importância reveste-se de atualidade pelos incontáveis dados da realidade eternizados por fontes documentais, traduzem-se numa violência que desconhece limites para uma atuação legitimada por esta categoria de pessoas que detém o direito ao uso desmedido da força, que mata, altera a cena do crime, que forja uma suposta resistência e ainda ameaça a convivência humana.

Os desvios das polícias frequentemente permanecem impunes, segundo CHAVIGNY (2000, p.65) o papel da polícia na América Latina foi definido erroneamente, pois “muitos políticos de forma impensada aceitam um modelo semimilitar no qual o papel da polícia é ‘combater' o inimigo ‘crime’, incorporado à pessoa do criminoso”.

Assim, o fosso da corrupção criado no Brasil alimenta a desproteção da coletividade através de suas instituições, órgãos e agentes públicos que deveriam estar comprometidos em ser interlocutores de uma massa difusa e indeterminada de pessoas que reclamam desempenhos satisfatórios para não só prevenir, reprimir e punir, mas também de que determinadas promessas de cidadania sejam efetivamente implementadas como consequência da dação de direitos civis, sociais e políticos.

Não se olvida negar que há o movimento crescente da violência urbana, que é pungente e ocorre de um modo particularizado no interior das favelas que de modo periférico faz proliferar a miséria, a ausência de condições de vida e de trabalho.

De certo é que, esses agrupamentos humanos já convivem historicamente com um cotidiano alijador de direitos sociais e fundamentais para o processo de visibilidade dentro de uma megalópole. Segundo ADORNO (1995, p. 301): 
Ao longo de mais de cem anos de vida republicana, a violência em suas múltiplas formas de manifestação permaneceu enraizada como modo como modo costumeiro, institucionalizado e positivamente valorizado - isto é, moralmente imperativo -, de solução de conflitos decorrentes das diferenças étnicas, de gênero, de classe, de propriedade e de riqueza, de poder, de privilégio, de prestígio. Permaneceu atravessando todo o tecido social, penetrando em seus espaços mais recônditos e se instalando resolutamente nas instituições sociais e políticas em princípio destinadas a ofertar segurança e proteção aos cidadãos.

A compreensão do modelo e da forma de instituição da violência está na dimensão do poder, da pobreza e da exclusão. Nesse passo, surge um terreno fértil para movimentos desastrosos organizados pelo Estado, monopolizadores e pacificadores, que afugentam o pertencimento social dos moradores das favelas, transformando-os cada vez mais em vítimas de uma conjuntura desigual de direitos.

Essa desigualdade, seja qual for o plano, faz emergir os mais variados conflitos em grande monta os que são criados por abuso de autoridade e violência policial. Os moradores são vistos em sua grande parte como suspeitos ou marginais, sem que lhes sejam garantidas à presunção de inocência. São considerados réus pelo simples fato de serem moradores de favelas ou supostamente aparentarem sinais diacríticos marginalizadores.

Nesse sentido o atual modelo proposto de atuação coexiste com a violência e a utilização indiscriminada do uso de armas de fogo, em abordagens policiais que ensejam um contexto de confrontos, violações de domicílio, execuções sumárias e intimidação permanente.

Por vezes, a ineficiência do modelo do aparelho policial é perpetuada e normalizada internamente nas corporações, ante ao sentimento de impunidade compartilhando entre seus pares. Para MUNIZ (2006):

(...) A visão de que os policiais possuem bem mais poderes do que os cidadãos que policiam, permite uma leitura da discricionariedade como um expressivo acréscimo de poder policial. Num jogo de relações já pontuadas pela assimetria, este suposto "poder a mais" pode ser percebido como um sobrepeso que faria a balança pender ainda mais para o lado daqueles agentes que controlam, coagem e custodiam. Aos olhos do senso comum, a desproporção de recursos é mais palpável nas interações entre policiais e cidadãos do que nas relações de poder estabelecidas entre outros profissionais e o seu público. Diante dessa evidência é razoável supor que o 


\section{CONTROLE, INTERVENÇÃO E NECROPOLÍTICA: UMA TOPOGRAFIA DA VIOLÊNCIA URBANA NAS FAVELAS DO RIO DE JANEIRO}

decisionismo policial possa vir a ser objeto de uma espécie de desconfiança coletiva prévia. E isto de tal forma que a discricionariedade policial pode ser apreendida como algo que se suspeita por antecipação, requerendo uma vigilância redobrada dos que policiam e uma dúvida estruturante por parte dos cidadãos policiados.

A retórica policial de preservar as liberdades e a vida parecem não produzir valor na história coletiva dos moradores de favelas. A rotina conhecida e experimentada pelos moradores de favelas é a da violência e exclusão. Neste aspecto a legitimação para a convivência não acontece no modo desejado por estes moradores, ou seja, o espaço não é reconfigurado e sim perpetuado numa capilaridade territorial, histórica e dimensional que permanece em dominação assincrônica entre moradores e pelos desarranjos públicos.

Essa circunstância demonstra que há uma instrução, um regramento interno legitimado por códigos a fim de restringir liberdades individuais dentro de argumentos repressivos malfadados para a condução de políticas repressivas de uma camada populacional no interior do trato urbano que deveria ser integrador.

A representação analítica parece ser sintetizada por discernimento pessoal, simplesmente porque alguns moradores são vistos como desinteressantes, infames e indesejáveis ao Estado, por critérios subjetivos construídos a partir de estereótipos por razões de ordem prática e não investigativa.

Nessa miríade de informações há dados analíticos que demonstram a postura de crueldade e insensibilidade por parte dos policiais militares e sua (i)lógica atuação no sofrimento alheio, o que acaba por promover uma segregação espacial do perigo nas favelas, onde o alto índice dos crimes violentos acirram os discursos de ódio entre moradores e agentes públicos.

É preciso ainda mencionar que não só a truculência em ações onera os custos de todo um sistema e que dificultam inclusive a execução de outras políticas públicas de importância, mas, também a corrupção policial, o tráfico de drogas e armamentos efetivados por militares de alto coturno perpetrados no terreno fértil da impunidade.

Para BELTRAME (2014, p. 76-77): 
A cidade assistiu à violência crescer como uma chaga e nada fez para detê-la. As favelas se expandiram a olhos vistos, com barracos construídos sobre encostas e córregos, ante a apatia da população, da justiça e dos governos municipal e estadual. O descaso teve como consequência a insegurança. Foi desse vácuo legislativo e do poder público que se aproveitaram as quadrilhas para tomar conta da região. Todo esse problema do Rio passa pela desordem pública. É o que pavimenta o caminho para o crime, para a insegurança dos cidadãos. Parte da polícia acabou seduzida pela contravenção, pelo tráfico, pela birosca da esquina, pela ilegalidade de um estacionamentoindevido.

Do exposto acima percebe-se que os representantes do Estado reconhecem que o retrato dessa corporação policial é conhecido, o que em alguns casos resultam em expulsão das fileiras, não importando a patente, o que torna clara uma realidade patológica, uma doença, uma praga, um quisto, uma calamidade pública (PARISSE, 1969).

Em apoio, podemos dizer que nossa polícia mata no atacado, mas, também morre no varejo vitimada pela sanha de deglutir as entranhas de um espaço social desintegrado. O perecimento da vida humana no cotidiano alimenta essas bases estatísticas. Mas, como são desimportantes esses indivíduos são facilmente esquecidos pelo Estado.

A favela enquanto local à deriva transforma os seus moradores em massa de vida sem valor condicionadas às fronteiras da dor e da falta de reconhecimento dos seus cidadãos, vez que, o movimento de cultura institucional das polícias é diacrônico e calcado em ações militarizadas de enfrentamento desproporcional para a regulação da ordem social, condenando seus pares a uma morte silenciosa ou simbólica.

\subsection{RIO, UMA CIDADE SITIADA: DESSA VEZ, COM A PALAVRA, A INTERVENÇÃO FEDERAL}

Ao nos debruçarmos sobre a pauta de segurança no Rio de Janeiro fica patente a ineficácia das políticas públicas, ora pela falta de investimentos, ora pela ausência de estratégia e inteligência nas ações conjugadas pela polícia militar. 


\title{
CONTROLE, INTERVENÇÃO E NECROPOLÍTICA: UMA TOPOGRAFIA DA VIOLÊNCIA URBANA NAS FAVELAS DO RIO DE JANEIRO
}

Para HALLOWAY (1997, p. 50):

\begin{abstract}
O inimigo da polícia do Rio de Janeiro era a própria sociedade - não a sociedade como um todo, mas os que violavam as regras de comportamento estabelecidas pela elite política que criou a polícia e dirigia a sua ação. Com efeito, a manutenção de uma estrutura militarizada se sustenta em função das representações sociais sobre os pobres enquanto classe perigosa que perdura no imaginário social das elites conservadoras brasileiras.
\end{abstract}

Por essas razões pragmáticas foram instituídas as Operações de Garantia da Lei e da Ordem (GLO) para produção da sensação de estabilidade do exercício do governo como ferramenta de combate às organizações criminosas.

Sob o argumento de retomada das práticas inerentes à segurança pública foi ancorada “Intervenção Federal”, cujo manejo é de competência do governo federal que assume o papel de garantidor das vidas humanas na cidade do Rio de Janeiro. A intervenção federal promulgada através do Decreto Presidencial de $\underline{n}^{\circ}$ 9.288, de 16 de fevereiro de 2018, objetiva colocar termo ao grave comprometimento da ordem pública e demonstra da forma mais cruel a crise em que o Rio de Janeiro está mergulhado.

Afastado o Secretário de Segurança foi nomeado interventor o general Walter Souza Braga Netto como interventor e a população fica à mercê de possíveis enfrentamentos agora protagonizados pelo Exército.

Ao nosso juízo a população vulnerabilizada será obrigada a conviver com as legislações formais desgastadas e intervenções extralegais violentas.

Estudos endossados por pesquisadores demonstram a necessária elaboração de uma Plano de Segurança Pública com objetivos e metas que possam ser monitoradas e avaliadas.

Estudiosos como MISSE$^{7}$ afirmam que do ponto de vista político essa talvez tenha sido uma jogada de mestre do Presidente Michel Temer. Desfocando sua (in)governabilidade e

https://oglobo.globo.com/rio/artigo-unica-justificativa-para-uma-intervencao-seria-combater-corrupcao-de-agentes-doestado-22410711

Revista de Sociologia, Antropologia e Cultura Jurídica| e-ISSN: 2526-0251 | Salvador | v. 4 | n. 1 | p. 41 - 63 | Jan/Jun. 2018 
sua ilegitimidade colocou como pauta de observação a problemática no entorno da segurança pública. Afastando outros julgamentos de ordem como a corrupção deflagrada pela Operação Lava-Jato e até mesmo a reforma da Previdência Social.

Essa compreensão é corroborada pelos dados numéricos publicados pelo Fórum Brasileiro de Segurança Pública ${ }^{8}$, relativos ao ano de 2016, que constatam que o Rio de Janeiro é apenas o $11^{\circ}$ Estado em termos de taxa de morte violenta intencional.

É preciso questionar, sob o ponto de vista acadêmico, se a intervenção federal com o aparato militar produzirá o resultado propagado pelo Poder Público. Em regra, essas manobras apresentam-se custosas, de baixo resultado e com possibilidade de propagação de mais abusos de autoridade.

Para o diretor da ONG Redes da Maré, Edson Diniz ${ }^{9}$ essa lógica da guerra só prejudica os mais pobres: “Esse tipo de segurança que vê a favela como inimiga não dará certo nunca”.

Nesse contexto fica como necessário ponto de partida e orientação o efeito da coerência como valor jurídico e político da intervenção federal como mecanismo histórico que é estranho na relação de tensão e equação com vistas ao esgotamento de outros recursos destinados à preservação da ordem pública.

Afetação e o estímulo do medo não seriam um ardil para o controle da sociedade? A intervenção federal foi decretada para justificar a falta de controle social? Curiosamente os índices de violência no Estado do Rio de Janeiro aumentou exponencialmente. De modo explícito a sensação de insegurança é latente, especialmente depois do homicídio da Vereadora Marielle Franco e seu motorista Anderson Gomes.

A instituição da lógica de uma "guerra contra o território inimigo" acirra o discurso de ódio, indicando que a intervenção federal aprofundou a violência de todos os dias.

Não é de se estranhar que para a população favelada, o tratamento dispensado de antecipação de riscos foi eleito como tema revisitado pelos oficiais das forças armadas como revistas em bolsas e afins, identificação a partir de fotografias dos moradores junto às identidades civis para fichamentos, mandados coletivos de busca e apreensão etc. ${ }^{10} \mathrm{Com}$ clareza

\footnotetext{
${ }^{8}$ http://www.forumseguranca.org.br/wp-content/uploads/2018/04/FBSP_Rio_sob_Intervencao_2018_relatorio.pdf

${ }^{9}$ https://adufrj.org.br/noticia/o-que-e-preciso-saber-sobre-a-acao-do-exercito-no-rio/

10 Em reportagem a Revista Veja de 13 de março de 2018 asseverou: "Defensoria e OAB condenam 'fichamento' de moradores no RJ. Para entidades, procedimento adotado por militares viola garantias individuais; Forças Armadas dizem que iniciativa é legal e rotineira. A Ordem dos Advogados do Brasil no Rio de Janeiro e a Defensoria Pública no estado manifestaram-se contra o "fichamento" de moradores de comunidades fluminenses
} 


\section{CONTROLE, INTERVENÇÃO E NECROPOLÍTICA: UMA TOPOGRAFIA DA VIOLÊNCIA URBANA NAS FAVELAS DO RIO DE JANEIRO}

meridiana o princípio da presunção da inocência constantemente é violado por reiteradas condutas estatais.

De certo que, a intervenção federal como se operacionaliza no Rio de Janeiro enfraquece os instrumentos democráticos do Estado de Direito reverberando a chamada violência institucional.

Tais práticas que antes eram realizadas pelos policiais militares através de uma violência intencional legal começa a ganhar força para a execução de uma política de segurança pública comprovadamente fracassada que vem produzindo horror e dor, cujo preço é pago, principalmente, com vidas de jovens negros moradores das periferias e favelas por que são selados pela suspeita ${ }^{11}$ agora pelo Exército brasileiro.

Não por acaso, o arbítrio policial e formas paralelas de controle ocupam lugar de destaque na vida dos moradores da periferia urbana. É neste sentido que se pode afirmar que a favela se converteu no espaço paradigmático para o exercício de uma peculiar economia da violência: a distribuição calculada da morte e da punição como instrumentos políticos de controle territorial [...]. Isso equivale a sustentar que, no caso brasileiro, a nova "arte de governar" tem racionalidades múltiplas: ela opera simultaneamente na produção espacial da favela como lugar da desordem e do crime [...], na disciplina espaço-corporal a partir do trabalho "pedagógico" de conselhos comunitários de segurança e das ONGs com foco nos jovens tidos como "problema social", e nas intervenções estatais letais (necropráticas), como dão conta as ações policiais resultantes nos famigerados "autos de resistência" ou "resistência seguida de morte". (ALVES, 2011, p.117-118).

\footnotetext{
por militares durante a intervenção na segurança pública. O procedimento, sob argumento de checagem de antecedentes criminais, foi realizado nesta sexta-feira (23) em operação na Vila Kennedy, na zona oeste da capital fluminense. Para as entidades, a medida viola a Constituição. Segundo as Forças Armadas, a iniciativa é legal e rotineira."

11 Segundo RAMOS; MUSUMECI (2005, p.113): “A ocorrência de revista corporal também varia sensivelmente conforme idade, gênero, cor e classe social da pessoa abordada. Os jovens, os negros e as pessoas de renda e escolaridade mais baixas sofrem revista em proporções bem maiores do que os outros segmentos considerados. Ao que tudo indica, a polícia não só suspeita menos de pessoas brancas, mais velhas e de classe média que transitam pelas ruas da cidade, como tem maior "pudor" em revistá-las - um procedimento muito fortemente associado à existência de suspeição, e via de regra, considerado humilhante".
} 
Por essa razão, a inquietação desse discurso permanece diante de um olhar desafiador para a compreensão e questionamento das tensões e os conflitos gerados nesses espaços de moradia onde a revelação dos rituais de desprezo, humilhação, desproteção e desrespeito por parte de "agentes de segurança” incitam a violência e perpetuam suas convicções de manutenção das relações de poder, pois afinal de contas, ali estão presentes os inimigos do Estado.

\subsection{INCONSTITUCIONALIDADE DA INTERVENÇÃO FEDERAL DECRETADA NO RIO DE JANEIRO}

Há 128 anos o Brasil adotou, pelo Decreto $\mathrm{n}^{\circ}$ 1, de 15 de novembro de 1889, a forma de Estado federativo. No decorrer desse percurso de mais de um século, o país vivenciou momentos de síncope constitucional e incertezas durante os períodos de autoritarismo. As sete constituições, que foram adotadas no país, após a mudança das formas de Estado e de Governo, todas disciplinaram o federalismo.

Todavia, para a manutenção da própria federação, em virtude de atos que possam comprometer o pacto federativo, torna-se possível a suspensão temporária da autonomia política do ente federado. Na ordem constitucional vigente a intervenção federal é medida excepcionalíssima, prevista em hipóteses restritas. Por isso, os pressupostos materiais para a decretação da intervenção federal estão expressamente previstos no texto constitucional para a defesa: a) do Estado; b) do princípio federativo; c) das finanças do Estado e, finalmente, d) da ordem constitucional.

Apesar de não ter havido transparência nas razões que a justificaram, a intervenção federal no Rio de Janeiro foi formalizada através do decreto presidencial $n^{\circ}$ 9.288, de 16 de fevereiro de 2018. Em 20 de fevereiro o Congresso Nacional promulgou o Decreto Legislativo $n^{\circ} 10$ que aprovou o decreto presidencial com o objetivo de pôr termo ao grave comprometimento da ordem pública.

Entre outros dispositivos, o referido decreto destaca que a medida durará até 31 de dezembro; se limita à área de segurança pública do Estado do Rio de Janeiro; nomeia como interventor um General do Exército brasileiro e que o cargo de Interventor se reveste de natureza militar.

A intervenção federal no Rio de Janeiro apresenta característica militar e se apoia na ideia de conflito armado e gradual militarização da Segurança Pública, o que a torna inconstitucional. Como substituir um cargo civil ocupado pelo Governador do Estado no comando da segurança pública por um cargo de natureza militar? Tal fato pode gerar inclusive responsabilidade do próprio Presidente da República. Questiona-se ainda a falta de oitiva prévia 


\section{CONTROLE, INTERVENÇÃO E NECROPOLÍTICA: UMA TOPOGRAFIA DA VIOLÊNCIA URBANA NAS FAVELAS DO RIO DE JANEIRO}

dos Conselhos da República e o Conselho da Defesa Nacional, já que o Decreto interventivo foi editado antes dos pareceres dos dois órgãos.

Resta sublinhar que várias Organizações apresentaram uma representação à Procuradoria-Geral da República para que esse órgão possa ajuizar Ação Direta de Inconstitucionalidade contra o Decreto de intervenção na segurança pública do Rio de Janeiro. Além disso, já tramita no Supremo Tribunal Federal a Ação Direta de Inconstitucionalidade ${ }^{0}$ 5915, na qual o Partido Socialismo e Liberdade questiona o mesmo decreto.

Embora se reconheça que a violência urbana aliada à crise econômica no Estado do Rio de Janeiro tem elevado o número de conflitos, a taxa de mortes violentas intencionais é de 37,6, por 100 mil habitantes, percentual abaixo de outros Estados, como Rio Grande do Norte, Pará e Alagoas. (FÓRUM BRASILEIRO DE SEGURANÇA PÚBLICA, 2017).

Apesar da decretação da intervenção federal, ainda que se imagine por eventual constitucionalidade do decreto presidencial $n^{0}$ 9.288, de 16 de fevereiro de 2018, o Rio de Janeiro continua à deriva, já que a medida não traz qualquer vantagem para os moradores do Estado.

\section{REPONSABILIDADE INTERNACIONAL DO ESTADO BRASILEIRO}

No âmbito internacional é possível projetar uma eventual responsabilidade do Estado, já que o Brasil faz parte do sistema regional de proteção de direitos humanos e é signatário da Convenção Americana desde 25 de setembro de 1992 e reconheceu a competência contenciosa da Corte Interamericana de Direitos Humanos em 10 de dezembro de 1998.

É importante destacar que a jurisdição internacional tem caráter convencional, coadjuvante e complementar à jurisdição nacional, não se tratando de uma quarta instância. Entretanto, a Corte Interamericana é competente para conhecer excepcionalmente de casos já analisados pelo Estado, desde que o interessado solicite a revisão da decisão proferida pelo Judiciário doméstico em virtude da incorreta apreciação da prova. ${ }^{12}$

\footnotetext{
${ }^{12}$ A jurisprudência da Corte Interamericana possibilita a análise do órgão como revisor das decisões internas, como ocorreu em: Caso Cabrera García e Montiel Flores Vs. México. Exceção Preliminar, Mérito, Reparações e Custas. Sentença de 26 de novembro de 2010. Série C N 220, par. 16; Caso García Ibarra e outros Vs. Equador.
}

Revista de Sociologia, Antropologia e Cultura Jurídica| e-ISSN: 2526-0251 | Salvador | v. 4 | n. 1 | p. 41 - 63 | Jan/Jun. 2018 
Em 2015, a Comissão Interamericana de Direitos Humanos submeteu à Corte um caso que envolveu violência policial no âmbito de uma favela no Rio de Janeiro. Tratou-se do caso Cosme Rosa Genoveva, Evandro de Oliveira e outros (Favela Nova Brasília) contra a República Federativa do Brasil.

Os fatos ocorreram na Favela Nova Brasília em 18 de outubro de 1994 e em 8 de maio de 1995 e referiram-se às falhas e à demora na investigação e punição dos responsáveis pelas execuções extrajudiciais de 26 pessoas no âmbito das incursões policiais feitas pela Polícia Civil do Rio de Janeiro, além de três crimes de violação sexual. Ressalta-se que o Estado brasileiro reconheceu que seus agentes (policiais) foram autores dos crimes, embora tais fatos, segundo o entendimento dos representantes brasileiros, extrapolassem a jurisdição da Corte Interamericana.

Evidencia-se que a violência policial representa um problema que exorbita as fronteiras do Estado brasileiro por representar uma questão de violação aos direitos humanos.

Por conta da insuficiência do Estado em resolver todas as questões que ultrapassam suas fronteiras torna-se claro o processo de esvaziamento da ordem constitucional e a consequente necessidade da busca de solução eficaz para um problema comum. Nesse sentido desponta o denominado transconstitucionalismo como um movimento que gravita a partir do entrelaçamento de ordens jurídicas distintas em torno dos mesmos problemas de ordem constitucional sem a sobreposição de decisões de um tribunal a outros, na busca do constante diálogo e troca de informações entra as jurisdições (NEVES, 2009).

De qualquer maneira, o Rio de Janeiro, ente que figura como um dos mais violentos do país, não possuía dados sobre mortes ocorridas durante operações policiais nos anos 1994 e 1995. A partir de 1998, a Secretaria de Segurança Pública do Rio de Janeiro começou a compilar essas estatísticas. Em 1998, foram 397 pessoas mortas por ação da polícia no Estado. Em 2007, o número de pessoas mortas chegou ao patamar de 1.330. Em 2014, foram 584 vítimas mortas pelas intervenções policiais e, finalmente, em 2015, o número de pessoas mortas foi de 645, no Estado do Rio de Janeiro ${ }^{13}$.

Exceções Preliminares, Mérito, Reparações e Custas. Sentença de 17 de novembro de 2015. Série C No 306, par. 17 a 22.

${ }^{13}$ Fórum Brasileiro de Segurança Pública, Anuário Brasileiro de Segurança Pública 2015. São Paulo, 2015. 


\title{
CONTROLE, INTERVENÇÃO E NECROPOLÍTICA: UMA TOPOGRAFIA DA VIOLÊNCIA URBANA NAS FAVELAS DO RIO DE JANEIRO
}

A sentença da Corte Interamericana de Direitos Humanos proferida em 16 de fevereiro de 2017, que resolveu sobre as exceções preliminares, mérito, reparações e custas, que condenou o Estado brasileiro no caso Favela Nova Brasília asseverou que:

\begin{abstract}
Entre as vítimas fatais de violência policial, estima-se uma predominância de jovens, negros, pobres e desarmados. Segundo dados oficiais, “os homicídios são hoje a principal causa de morte de jovens de 15 a 29 anos no Brasil, e atingem especialmente jovens negros do sexo masculino, moradores das periferias e áreas metropolitanas dos centros urbanos. Dados do SIM/Datasus do Ministério da Saúde mostram que mais da metade dos 56.337 mortos por homicídios, em 2012, no Brasil, eram jovens (30.072, equivalente a $53,37 \%$ ), dos quais $77,0 \%$ negros (pretos e mulatos) e $93,30 \%$ do sexo masculino". Na cidade do Rio de Janeiro, aproximadamente $65 \%$ das pessoas que morreram em 2015 são negras (negros e mulatos). No Estado do Rio de Janeiro, estudos mostram que a oportunidade de um jovem negro de morrer por ação da polícia é quase 2,5 vezes maior do que a de um jovem branco.
\end{abstract}

Curiosamente, o Estado brasileiro em 1996 reconheceu perante à Organização dos das Nações Unidas - ONU, no Comitê de Direitos Humanos, que o Estado necessitava tomar providências para ultimar com a impunidade das violações dos direitos humanos conferidas aos agentes policiais (ORGANIZAÇÃO DAS NAÇÕES UNIDAS, 1996).

Organizações não-governamentais, como por exemplo, a Anistia Internacional, analisam extensivamente a violência que caracteriza o policiamento em favelas.

O policiamento das favelas consiste, sobretudo, em controlar o crime dentro das comunidades, cujo único contato com o Estado acontece por meio de uma força policial que é geralmente brutal e corrupta. A presença policial nessas comunidades costuma se dar na forma de grupos invasores que trocam tiros com os criminosos e aterrorizam os moradores. Essa presença raramente resulta em qualquer tipo de proteção prolongada, se é que isso alguma vez acontece. (ANISTIA INTERNACIONAL, 2008, p. 42)

Além disso, as incursões policiais afetam a economia das favelas envolvidas, conforme analisa a Anistia Internacional:

No Rio de Janeiro, os moradores das comunidades de Vila Cruzeiro e do Complexo do Alemão tiveram de suportar vários meses de confrontos constantes entre a polícia e os traficantes de drogas, desde o final de 2006 até meados de 2007. O 
policiamento do Rio de Janeiro continua a ser caracterizado por operações de grande escala em que unidades policiais fortemente armadas "invadem" as favelas e depois se retiram quando a operação termina. Para as comunidades, o custo dessas operações é muito alto. Elas põem em risco a vida de todos, inclusive a dos policiais. Os danos à propriedade e à infra-estrutura, o fechamento de negócios e a necessidade de obedecer a toques de recolher impedem que as pessoas trabalhem e estudem. Os custos sociais e financeiros persistem por muito tempo depois que a operação é concluída. E assim que a polícia se retira, as facções do tráfico retomam o controle. Os problemas subjacentes da exclusão social e da criminalidade são deixados intactos, enquanto a comunidade é castigada por ondas de violência criminal e policial. (ANISTIA INTERNACIONAL, 2008, p. 43) 
O CASO DA FAVELA NOVA BRASÍLIA ILUSTRA O QUE JÁ SE CONHECIA A PARTIR DO RELATÓRIO SOBRE A SITUAÇÃO DOS DIREITOS HUMANOS NO BRASIL, DE 1997. A COMISSÃO INTERAMERICANA DE DIREITOS HUMANOS JÁ HAVIA SALIENTADO QUE AS MORTES OCORRIDAS DURANTE AS INTERVENÇÕES POLICIAIS NAS FAVELAS ERAM REGISTRADAS COMO LEGÍTIMA DEFESA, EMBORA AS AUTÓPSIAS REALIZADAS NAS VÍTIMAS GERALMENTE DEMONSTRASSEM QUE AS MORTES OCORRIAM POR DISPAROS EM REGIÕES VITAIS DO CORPO HUMANO. ALÉM DISSO, ESSAS MORTES FICAM IMPUNES, POIS NÃO SÃO ADEQUADAMENTE INVESTIGADAS.

A DIFICULDADE DE INICIAR INVESTIGAÇÃO DE HOMICÍDIO OCORRIDO EM FAVELAS DO RIO DE JANEIRO DERIVA DO FORMULÁRIO DE RESISTÊNCIA À PRISÃO E ANTES DE REALIZAR QUALQUER INVESTIGAÇÃO A RESPEITO, VERIFICA-SE O PERFIL DA VÍTIMA FALECIDA E SE ENCERRA POSSÍVEL INVESTIGAÇÃO POR CONSIDERA-LA CRIMINOSA. OU SEJA, É A PRÓPRIA POLÍCIA, QUEM REGISTRA O CASO COMO “ATOS DE RESISTÊNCIA” OU “RESISTÊNCIA SEGUIDA DE MORTE” O QUE INVIABILIZA QUALQUER INVESTIGAÇÃO SÉRIA.

NESSA ORDEM DE IDEIAS ASSEGURAR DIREITOS FUNDAMENTAIS DESTINADOS À PROTEÇÃO DO GÊNERO HUMANO É UM CONSTANTE REPENSAR SOBRE A APLICABILIDADE DO DIREITO. EM CONSEQUÊNCIA, DENTRO DESSA PERSPECTIVA EVITA-SE, DENTRO DO POSSÍVEL, A RESPONSABILIDADE INTERNACIONAL DO ESTADO BRASILEIRO MAIS UMA VEZ NO ÂMBITO DO SISTEMA REGIONAL DE PROTEÇÃO DOS DIREITOS HUMANOS.

\section{CONSIDERAÇÕES FINAIS}

Com este trabalho pretendeu-se demonstrar como se percebe de forma muito peculiar que o Estado do Rio de Janeiro está à deriva, mesmo após a decretação da intervenção federal pelo Presidente da República. O colapso na Segurança Pública e seu desfuncionamento não são capazes de demonstrar na inteireza os sentimentos dos cidadãos, especialmente, dos desvalidos que habitam as favelas cariocas. 
A escalada excessiva da violência e da decadente pauta política de tangenciamento de crises consiste num inédito ato que atenta contra o Estado Democrático de Direito definindo o Estado do Rio de Janeiro como um Estado falido que desumaniza e marginaliza um coletivo de pessoas moradoras da favela, especialmente quando agentes do Estado impõem medidas para o contingenciamento da violência, como por exemplo, o fichamento de moradores da favela, revistas a pertences sem fundada suspeita e a concessão de mandados de busca e apreensão coletivos.

Medidas tomadas por agentes policiais do Estado, que desrespeitem paradigmas basilares da Convenção Americana e outros tratados dos quais o Brasil faz parte, no âmbito de uma intervenção federal militarizada, pode ocasionar para o Estado brasileiro responsabilidade internacional perante o sistema regional de proteção de direitos humanos, como aconteceu no caso Favela Nova Brasília, julgado em 2017 pela Corte Interamericana.

As divergências que afetam as premissas orientadoras da segurança pública e o princípio da dignidade da pessoa humana, em verdade, perpetuam a insegurança e tornam a instituição policial militar desacreditada quando o cidadão é selado pela marca da exclusão: preto, pobre e favelado. Essa dimensão desabonadora impregnada de preconceito, racismo e olhar marginalizador passa a ser um elemento fundamental dessa tragédia cotidiana que relega os moradores das favelas ao confinamento do caos social, que sem voz, permanecem distanciados de uma sociedade plural agora também pelos vieses interventivos.

Nessa ordem de ideias assegurar direitos fundamentais destinados à proteção do gênero humano é um constante repensar sobre a aplicabilidade do direito. E, nesse ponto fica evidente que nas favelas tornou-se extremamente frágil o exercício da cidadania e sua proteção, exigindo esforços para a fraternidade e solidariedade aos direitos considerados de terceira geração.

É inegável que desrespeitadas as premissas do direito constitucional, tende pela história soberana do Poder Estatal, a ocultar as violências perpetradas pelos agentes Estado no próprio espaço jurídico. Restando então caracterizada que atualmente as vidas humanas dos cidadãos cariocas estão passíveis de controle, punição e eliminação. Esse é o teorema que revela o drama social desta realidade conflagrada. 


\section{REFERÊNCIAS}

ABREU, M. de A. Reconstruindo uma história esquecida: origem e expansão inicial das favelas do Rio de Janeiro. In Espaço e Debates. São Paulo: NERU, n³7, pp34-46, 1994

ADORNO, Sérgio. A violência na sociedade brasileira: um painel inconcluso em uma democracia não consolidada. In: Estado e Sociedade/Departamento de Sociologia da Universidade de Brasília. Brasília, v. X, n. 2, jul./dez 1995, p. 299-342.

AGAMBEN, Giorgio. Homo sacer: o poder soberano e a vida nua. Belo Horizonte: Editora UFMG, 2010.

ALVES, Jaime Amparo. Topografias da violência: necropoder e governamentalidade espacial em São Paulo. Revista do Departamento de Geografia - USP, São Paulo, Volume 22, p. 108134, 2011.

ANISTIA INTERNACIONAL. Por trás do silêncio. Experiências de mulheres com a violência urbana no Brasil. Londres, 2008.

BELTRAME, José Mariano. Todo dia é segunda-feira. Rio de Janeiro: Sextante, 2014.

CARVALHO, J. M. CIDADANIA NO BRASIL: O LONGO CAMINHO. RIO DE JANEIRO: CIVILIZAÇÃO BRASILEIRA, 2005.

CARVALHO, IGOR. FARDAS CINZAS, CORPOS NEGROS. REVISTA CAROS AMIGOS. SÃO PAULO. ANO XIX. Nº 84, DEZ 2016, P. 5-7.

CHALHOUB, Sidney. Trabalho, lar e botequim: o cotidiano dos trabalhadores no Rio de Janeiro da belle époque. São Paulo: editora da Unicamp, 2001.

COMISSÃO INTERAMERICANA DE DIREITOS HUMANOS. Relatório sobre a Situação dos Direitos Humanos no Brasil, OEA/Ser.L/V/II.97, Doc. 29 rev. 1, 29 de setembro de 1997.

FÓRUM BRASILEIRO DE SEGURANÇA PÚBLICA. Anuário Brasileiro de Segurança Pública 2015. São Paulo, 2015. 
FÓRUM BRASILEIRO DE SEGURANÇA PÚBLICA. Anuário Brasileiro de Segurança Pública 2017. São Paulo, 2017.

FOUCAULT, M. Vigiar e punir: nascimento da prisão; tradução de Raquel Ramalhete. Petrópolis: Vozes, 1987.

. Em defesa da sociedade: Curso no Collège de France (1975 - 1976). SP: Ed. Martins Fontes, 2000.

A verdade e as formas jurídicas. Rio de Janeiro: NAU Editora, 2003.

História da sexualidade I: a vontade de saber. Rio de Janeiro: Graal, 2006.

HOLLOWAY, Thomas H. (1997). Polícia no Rio de Janeiro: repressão e resistência numa cidade do século XIX. Rio de Janeiro: Editora FGV.

PARISSE, Luciano. Favelas do rio de janeiro, evolução-sentido. Rio de janeiro: CENPHA, 1969.

MAC GREGOR, Helena C. Necropolítica: la política como trabajo de muerte. Ábaco. Revista de Cultura y Ciencias Sociales, $n^{\circ}$ 78, 2013.

MBEMBE, Achille. Necropolitics. Public Culture, 15, 2003.

MBEMBE, Achille. Necropolítica, una revisión crítica. In: GREGOR, Helena Chávez Mac (Org.). Estética y violencia: Necropolítica, militarización y vidas lloradas. México: UNAMMUAC, 2012.

NEVES, Marcelo. Transconstitucionalismo. São Paulo: Martins Fontes, 2009.

ZACCONE, Orlando. Indignos de vida: a forma jurídica da política do extermínio de inimigos na cidade do Rio de Janeiro. Rio de Janeiro: REVAN, 2015.

MISSE, Michel. Malandros, marginais e vagabundos \& a acumulação social da violência no Rio de Janeiro. Tese (Doutorado) - Instituto Universitário de Pesquisas do Rio de Janeiro, 1999. 


\section{CONTROLE, INTERVENÇÃO E NECROPOLÍTICA: \\ UMA TOPOGRAFIA DA VIOLÊNCIA URBANA NAS FAVELAS DO RIO DE JANEIRO}

ORGANIZAÇÃO DAS NAÇÕES UNIDAS. Comitê de Direitos Humanos. Ata resumida da 1506ª sessão. U.N. Doc. CCPR/C/SR.1506, par. 5. Nova York, 1992.

PERLMAN, Janice. O mito da marginalidade: favelas e política no Rio de Janeiro. $3^{\mathrm{a}}$ ed. Rio de Janeiro: Paz e Terra, 1977.

RAMOS, Sílvia; MUSUMECI, Leonarda. Elemento suspeito: abordagem policial e discriminação na cidade do Rio de Janeiro. Rio de Janeiro: Civilização Brasileira, 2005.

TAYLOR, Charles. Argumentos Filosóficos. São Paulo: Edições Loyola, 2000. Multiculturalismo: examinando a política de reconhecimento. Lisboa: Piaget, 1998.

VALIM, M. P.; CORREA, C. F. Todo Vagabundo Diz Que É Trabalhador. Esse Papo é Caô. Diálogos Sobre Direitos Humanos Fundamentais. 1. Ed. Rio De Janeiro: Lumen Juris, 2016. V. I. 107-116p.

VALIM, M. P.; OLIVEN, L. R. A. Entre Policiais E Policiados: A Intervenção violenta nas abordagens policiais em nome do Estado. In: Conselho Nacional De Pesquisa E Pós-Graduação Em Direito (Conpedi), 2016, Brasília, 2016. V. 1. P. 392-408. 